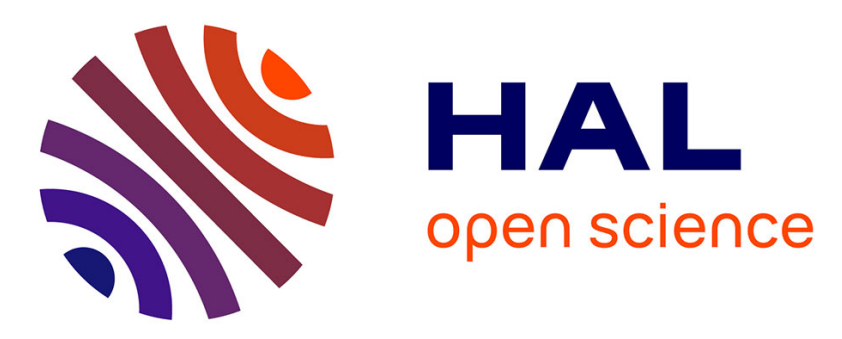

\title{
Tunable Localized Surface Plasmon Resonance and Broadband Visible Photoresponse of $\mathrm{Cu}$ Nanoparticles/ZnO Surfaces
}

Claudia de Melo, Maud Jullien, Yann Battie, Aotmane En Naciri, Jaafar Ghanbaja, François Montaigne, Jean-François Pierson, Federica Rigoni, Nils Almqvist, Alberto Vomiero, et al.

\section{To cite this version:}

Claudia de Melo, Maud Jullien, Yann Battie, Aotmane En Naciri, Jaafar Ghanbaja, et al.. Tunable Localized Surface Plasmon Resonance and Broadband Visible Photoresponse of Cu Nanoparticles/ZnO Surfaces. ACS Applied Materials \& Interfaces, 2018, 10 (47), pp.40958-40965. 10.1021/acsami.8b17194 . hal-02899428

\section{HAL Id: hal-02899428 \\ https://hal.univ-lorraine.fr/hal-02899428}

Submitted on 5 Jul 2021

HAL is a multi-disciplinary open access archive for the deposit and dissemination of scientific research documents, whether they are published or not. The documents may come from teaching and research institutions in France or abroad, or from public or private research centers.
L'archive ouverte pluridisciplinaire HAL, est destinée au dépôt et à la diffusion de documents scientifiques de niveau recherche, publiés ou non, émanant des établissements d'enseignement et de recherche français ou étrangers, des laboratoires publics ou privés. 


\section{Tunable Localized Surface Plasmon Resonance}

\section{and Broadband Visible Photo-response of $\mathrm{Cu}$}

\section{Nanoparticles/ZnO Surfaces}

Claudia de Melo ${ }^{\dagger}$, Maud Jullien ${ }^{\dagger}$, Yann Battie§, Aotmane En Naciri ${ }^{\S}$, Jaafar Ghanbaja ${ }^{\dagger}$, François Montaigne $e^{\dagger}$, Jean-François Pierson ${ }^{\dagger}$, Federica Rigoni", Nils Almqvist", Alberto Vomiero", Sylvie Migot ${ }^{*}$, Frank Mücklich+, David Horwat**

${ }^{\dagger}$ Université de Lorraine, CNRS, IJL, F-54000 Nancy, France

$\$$ Department of Materials Science and Engineering, Saarland University, D-66123 Saarbrücken, Germany

§ LCP-A2MC, Institut Jean Barriol, Université de Lorraine, 1 Bd Arago, 57070 Metz, France

॥ Department of Engineering Sciences and Mathematics, Division of Materials Science, Luleå University of Technology, 97187 Luleå, Sweden

KEYWORDS: copper nanoparticles, localized surface plasmon resonance, atomic layer deposition, hot electrons, photodetectors. 
ABSTRACT: Plasmonic $\mathrm{Cu}$ nanoparticles (NP) were successfully deposited on $\mathrm{ZnO}$ substrates by atomic layer deposition (ALD) owing to the Volmer-Weber island growth mode. An evolution from $\mathrm{Cu}$ NP to continuous $\mathrm{Cu}$ films was observed with increasing the number of ALD cycles. Real and imaginary parts of the NP dielectric functions, determined by spectroscopic ellipsometry using an effective medium approach, evidence a localized surface plasmon resonance that can be tuned between the visible and near infrared ranges by controlling the interparticle spacing and size of the NP. The resulting $\mathrm{Cu} \mathrm{NP} / \mathrm{ZnO}$ device shows an enhanced photo-response under white light illumination with good responsivity values, fast response times and stability under dark/light cycles. The significant photocurrent detected for this device is related with the hot electron generation at the NP surface and injection into the conduction band of the $\mathrm{ZnO}$. The possibility of tuning the plasmon resonance together with the photo-responsivity of the device is promising in many applications related with photo-detection, photonics and photovoltaics.

\section{Introduction}

Metal nanoparticles (NP), such as $\mathrm{Au}, \mathrm{Ag}$ and $\mathrm{Cu}$, have gained a lot of attention in multidisciplinary fields due to their outstanding optical and electrical properties. They exhibit localized surface plasmon resonance (LSPR), which comes from the coupling between the electromagnetic field and the collective oscillations of the free conduction electrons at the nanoparticle surface. With a precise control of the size, shape, density and dielectric environment, light can be manipulated and controlled in an exceptional manner. This is the reason why NP have drawn intense scientific and technological interest in many fields e.g. chemical sensing, ${ }^{1}$ catalysis, ${ }^{2}$ photonics,${ }^{3}$ and photovoltaics. ${ }^{4,5,6} \mathrm{Cu}$ NP have the advantage of their low cost compared with $\mathrm{Au}$ and $\mathrm{Ag}$. Moreover, $\mathrm{Cu}$ is already a material widely used in 
microelectronics, with high electrical conductivity and photosensitivity, ${ }^{7}$ making $\mathrm{Cu} \mathrm{NP}$ promising in applications related with nanoelectronics, optoelectronics, sensing, etc. ${ }^{8}$

$\mathrm{ZnO}$ is a low cost wide band gap semiconductor, with high exciton binding energy and high chemical stability, that has proven to be an excellent candidate for UV photodetection, light emitting diodes, transparent thin-film transistors, among others. ${ }^{9,}{ }^{10}$ In particular, $\mathrm{Cu}$ NP grown on $\mathrm{ZnO}$ act as catalysts in the methanol synthesis from $\mathrm{CO}_{2}$ hydrogenation ${ }^{11}$ and also for plasmonic energy conversion through hot-electron generation at the interface between the $\mathrm{Cu} \mathrm{NP}$ and $\mathrm{ZnO}$ films. ${ }^{12,13}$ The plasmonic effect in $\mathrm{Cu} \mathrm{NP}$ can boost the optoelectronic properties of $\mathrm{ZnO}$ by broadening the absorption band, enhancing the photocurrent and photocatalytic activity and allowing a wavelength-tunable photo-detection in the $\mathrm{Cu} / \mathrm{ZnO}$ devices by controlling the NP size, shape, density and agglomeration, for example. ${ }^{14,15}$

Examples of some of the different routes used for the fabrication of $\mathrm{Cu}$ NP are nanosphere lithography, ${ }^{16}$ electrochemical deposition, ${ }^{17}$ laser ablation in liquid media, ${ }^{7}$ and chemical reduction. ${ }^{18}$ Even if these methods enable the production of $\mathrm{Cu} \mathrm{NP}$, in some cases this is achieved on limited surface areas and/or using complex routes. In this paper we propose a different approach to fabricate highly responsive $\mathrm{Cu} \mathrm{NP} / \mathrm{ZnO}$ photodetectors using a simple atomic layer deposition (ALD) route. In a previous work we have already demonstrated the area selective $\mathrm{ALD}$ of $\mathrm{Cu}$ and $\mathrm{Cu}_{2} \mathrm{O}$ on $\mathrm{ZnO}$ substrates. ${ }^{19}$ In this paper the growth of $\mathrm{Cu} \mathrm{NP}$ on $\mathrm{ZnO}$ thin films is achieved at early stages of the deposition owing to the Volmer-Weber island growth mode. The optical responses of $\mathrm{Cu}$ NP, determined by spectroscopic ellipsometry using an effective medium approach are given and analyzed. It is shown that the LSPR of $\mathrm{Cu}$ NP can be tuned between the visible and near infrared ranges by controlling the interparticle spacing and size of the NP. Finally, the enhanced photo-response capability of the plasmonic $\mathrm{Cu} \mathrm{NP/ZnO}$ device is demonstrated by conductive atomic force microscopy 
(C-AFM) showing the potentialities of this technique for the fabrication of photo-detecting devices.

\section{Results and discussion}

$\mathrm{Cu} \mathrm{NP}$ were grown on $\mathrm{ZnO}$ thin films by ALD. Figure 1a-f shows top-view SEM micrographs of the $\mathrm{Cu} N \mathrm{NP}$ grown after 50 - 5000 ALD cycles; the lateral NP size $\left(\mathrm{NP}_{\mathrm{LS}}\right)$ distribution is shown as insets.

At early growth stages (50 cycles) we observe a random nucleation of $\mathrm{Cu}$ islands, with average $\mathrm{NP}_{\mathrm{LS}}$ and density of $9.5 \mathrm{~nm}$ and $4.7 \times 10^{10} \mathrm{~cm}^{-2}$, respectively. The formation of these small $\mathrm{Cu}$ NP dispersed on the $\mathrm{ZnO}$ substrate indicate a Volmer-Weber island growth mode at the first stages of deposition. ${ }^{20,21}$ Increasing the number of ALD cycles, the density is further increased as a result of the nucleation of new islands at "free" sites on the surface. However, after this first increase, the NP density tends to decrease monotonically with the number of ALD cycles as a result of the coalescence between adjacent islands. More precisely, for samples obtained at 500 cycles or more, there is a competition between coalescence and nucleation as can be verified in the histogram of Figure 1c that shows two NP populations, one with most likely size around $7 \mathrm{~nm}$ (due to nucleation) and a second one with most likely size around $24 \mathrm{~nm}$ (due to coalescence of smaller island). For $\mathrm{Cu}$ NP obtained after 3000 cycles, coalescence is clearly dominant and there is no secondary nucleation. This leads to a decrease in the density of particles while the surface coverage (see Figure 2a) and average $\mathrm{NP}_{\text {LS }}$ increase (see Figure $\mathrm{S} 1$ of supporting information).

In general, wide $\mathrm{Cu} \mathrm{NP} \mathrm{LS}_{\mathrm{L}}$ distributions were obtained as a result of different nucleation times. ${ }^{17}$ At 5000 cycles, most of the islands are interconnected due to the strong coalescence, which also leads to a much wider $\mathrm{NP}_{\mathrm{LS}}$ distribution (NP sizes ranging from 20 to $257 \mathrm{~nm}$ ). 
Moreover, at this point, as the surface is almost completely covered (surface coverage: $95 \%$ ), the growth of smaller particles is limited by their proximity with neighboring particles, which also contributes to the widening of the $\mathrm{NP}_{\mathrm{LS}}$ distribution.
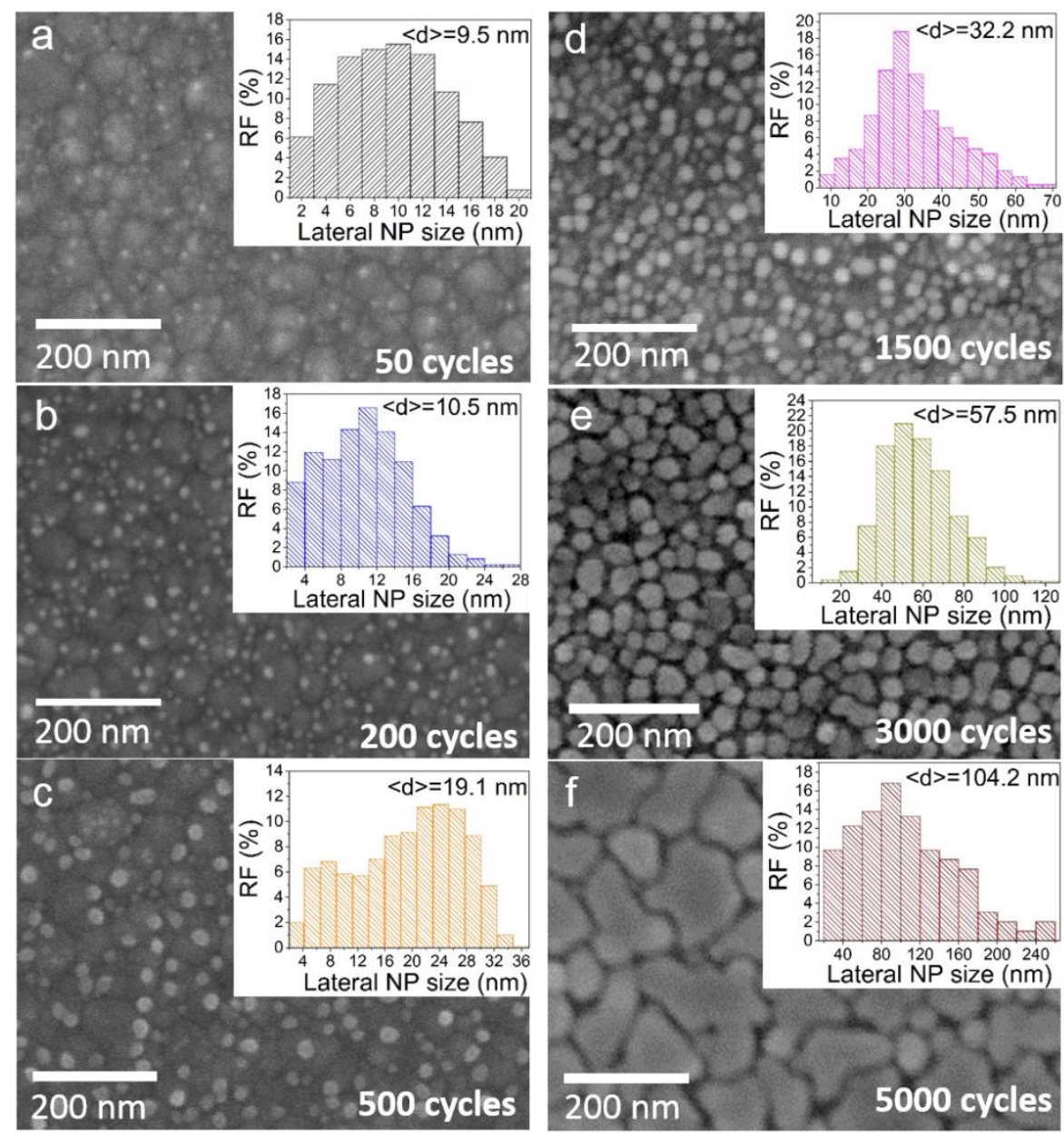

Figure 1. Top-view SEM micrographs of Cu NP at 50 (a), 200 (b), 500 (c), 1500 (d), 3000

(e) and 5000 (f) ALD cycles with the corresponding $\mathrm{NP}_{\mathrm{LS}}$ distributions at the inset (RF meaning relative frequency).

After 10000 cycles, a continuous $\mathrm{Cu}$ film is formed apart from some discontinuities between grains (see Figure S2 of Supporting Information). The thickness measured from cross-section TEM micrographs (Figure $2 b$ ) is in the $45-50 \mathrm{~nm}$ range. Resistivity values for this sample are in the $8-10 \mu \Omega \mathrm{cm}$ range. These values are in relatively good agreement with the resistivity of bulk copper $(1.68 \mu \Omega \mathrm{cm})$ considering electron scattering at film 
interfaces $^{22}$ due to the small thickness of the films which is comparable with the mean free path of conduction electrons in $\mathrm{Cu}(40 \mathrm{~nm}) .{ }^{23}$

X-ray diffractograms of the $\mathrm{Cu} \mathrm{NP}$ obtained at different number of ALD cycles are shown in Figure 2c. $\mathrm{Cu}$ NP are preferentially oriented in the [111] crystallographic direction, as indicated by the very small peak associated to the (200) crystallographic planes compared to the (111) peak. The intensity of the (111) Cu peak increases with the number of ALD cycles as a result of the increase in thickness, size of $\mathrm{Cu}$ NP and surface coverage. An XPS spectrum for a typical $\mathrm{Cu} \mathrm{NP/ZnO} \mathrm{sample} \mathrm{can} \mathrm{be} \mathrm{found} \mathrm{in} \mathrm{Figure} \mathrm{S3} \mathrm{of} \mathrm{Supporting} \mathrm{Information.}$

A cross-section high-resolution TEM (HR-TEM) micrograph of the sample obtained at 10000 ALD cycles is displayed at the inset of Figure 2b. The fast Fourier transform (FFT) pattern taken at this region is displayed at the corner. It is possible to identify the (111) and (200) planes of $\mathrm{Cu}$. The interplanar distance was measured to be 0.21 and $0.18 \mathrm{~nm}$ for the (111) and (200) planes, respectively, in good agreement with those reported for fcc $\mathrm{Cu}$ (PDF 04-0836), evidencing the good crystalline quality of the metallic $\mathrm{Cu}$ grown by this ALD route. The metallic character is also confirmed for $\mathrm{Cu} \mathrm{NP}$, as reported in Fig S4 of the Supporting Information. 

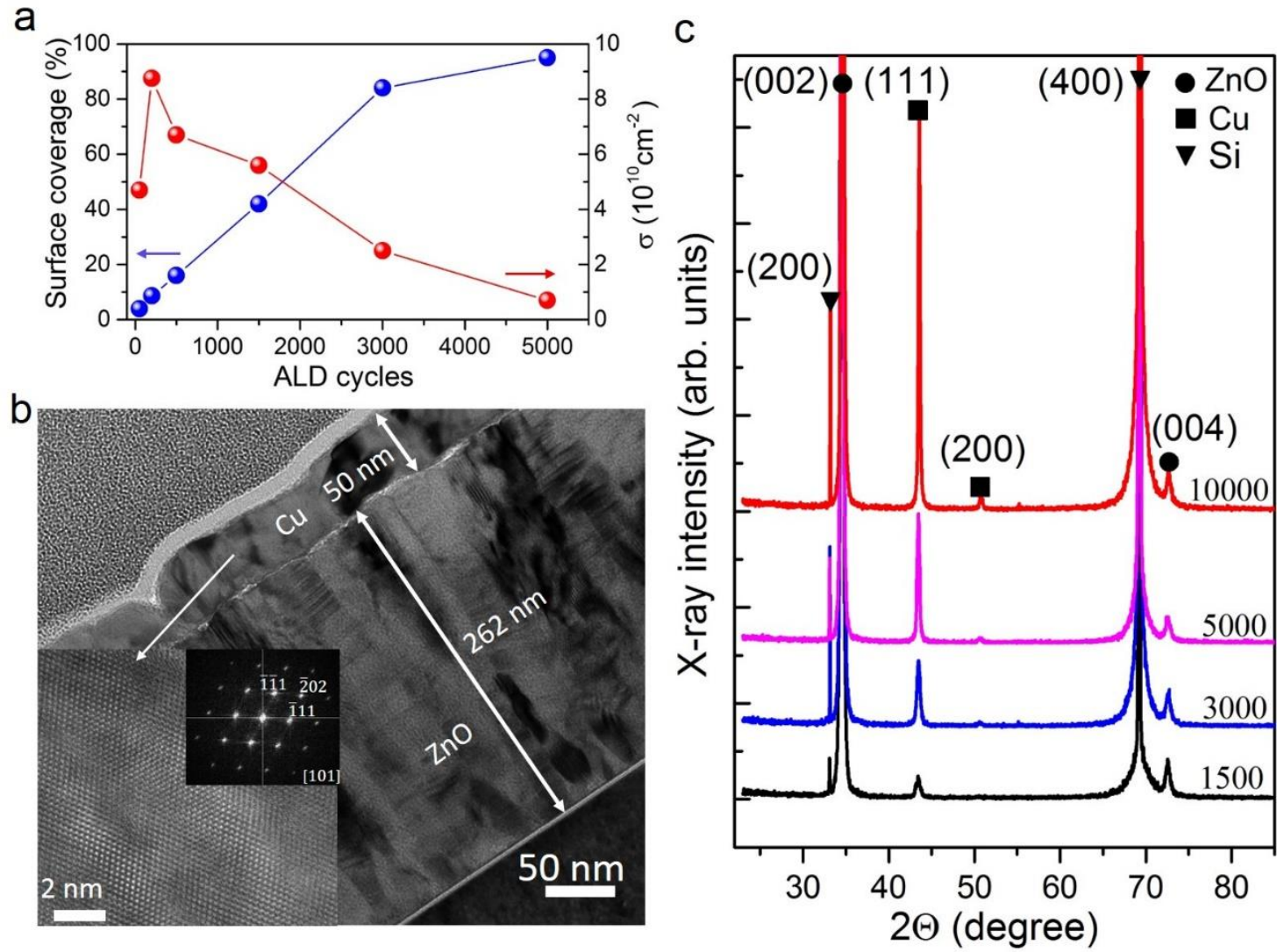

Figure 2. Surface coverage and density versus the number of ALD cycles (a). Cross-section TEM micrograph of the $\mathrm{Cu}$ film (10000 ALD cycles) and a HR-TEM micrograph with the corresponding FFT pattern at the inset (b). X-ray diffactrograms of the $\mathrm{Cu}$ NP deposited at 1500 (black), 3000 (blue) and 5000 (magenta) ALD cycles and the $\mathrm{Cu}$ film (red) deposited at 10000 ALD cycles (c)

\section{Localized surface plasmon resonance}

The presence of a LSPR band for the $\mathrm{Cu}$ NP was demonstrated by spectroscopic ellipsometry. The model employed for samples obtained after 1500, 3000 and 5000 ALD cycles is schematically represented in Figure 3a. The film stack consists in $\mathrm{Cu}$ NP deposited on a $\mathrm{ZnO}$ film grown on the $\mathrm{Si}$ substrate. In the case of the sample deposited at 10000 cycles, a $\mathrm{Cu}$ film with a certain porosity was considered since this film was thick enough to be opaque (details on the models to fit spectroscopic ellipsometric data are provided as Supporting Information, Figure S5, S6 and S7). 
Figure 3 shows the real (b) and imaginary (c) parts of the effective dielectric function. The imaginary part of the effective dielectric function $\left(\varepsilon_{\mathrm{i}}\right)$ for samples obtained at 1500 (black line), 3000 (blue line) and 5000 (violet line) cycles displays a LSPR band located at $697 \mathrm{~nm}$ $(1.78 \mathrm{eV}), 867 \mathrm{~nm}(1.43 \mathrm{eV})$ and $1127 \mathrm{~nm}(1.10 \mathrm{eV})$, respectively; which is accompanied by a large variation of the real part of the dielectric function $\left(\varepsilon_{\mathrm{r}}\right)$. Moreover, the amplitude of this variation in $\varepsilon_{\mathrm{r}}$ increases consistently with the LSPR peak intensity. LSPR bands are relatively wide and the full width at half maximum increases accordingly to the widening of $\mathrm{Cu} \mathrm{NP}_{\mathrm{LS}}$ distribution.

It is worth noting that $\varepsilon_{\text {r }}$ presents ranges with negative values for samples obtained at 3000 cycles and above. In this case, $\varepsilon_{\mathrm{r}}$ becomes negative for energy values between 516 and 826 $\mathrm{nm}(1.5-2.4 \mathrm{eV})$ and this behavior is more pronounced for the sample obtained at 5000 cycles. The negative values of $\varepsilon_{\mathrm{r}}$ are the result of NP coalescence: with increasing the number of cycles, $\mathrm{Cu}$ NP get in contact to form a compact layer (metallic behavior). However, they still support a plasmonic mode as confirmed by the presence of the LSPR band in $\varepsilon_{\mathrm{i}}$. Therefore, this sample presents an hybrid behavior between a metallic and a plasmonic material. ${ }^{24}$ For the sample obtained at 10000 cycles, $\varepsilon_{\mathrm{r}}$ is also negative but no plasmonic band is observed, indicating a metallic behavior. This result is expected since, in this case, a continuous metallic $\mathrm{Cu}$ film was formed, as verified by TEM and SEM micrographs.

As shown in Figure 3c, the LSPR band is red-shifted as the number of ALD cycles increases. This LSPR red-shift has already been observed for $\mathrm{Cu}$ NP with increasing particle size. ${ }^{16,17}$ However, such a large shift cannot be explained solely by the increase in NP size. Theoretical and experimental studies have shown that reducing the distance between Au NP produces a red-shift in the LSPR spectra. ${ }^{25,26,27}$ Additionally, the plasmon resonance depends strongly on particle shape. For example, changes in the geometry of the NP from circles to pentagons or triangles produce a significant shift in the plasmon signal ${ }^{28}$ and a red-shift has 
been predicted when spherical particles become more oblate. ${ }^{29}$ The formation of NP agglomerates, chains or complex networks can also produce an important broadening and red-shift of the plasmon resonance. ${ }^{30,31,32,24}$

In our case the red-shift is obviously mostly related to NP coalescence and the decrease in the inter-particular spacing which strengthen the coupling between different NP as they get closer to each other. In the case of sample grown with 5000 cycles, where particles as large as $257 \mathrm{~nm}$ are observed, NP size can also contribute to this red-shift. Nevertheless, the effect of NP shape cannot be completely ruled out, since an evolution in the geometry of $\mathrm{Cu}$ NP can be observed from sample grown at 1500 cycles to sample grown at 5000 cycles, and this could also influence the position and width of the LSPR band.

For all the samples, the spectra in Figure 3 are dominated by inter-band transitions below $540 \mathrm{~nm}$ (above $2.3 \mathrm{eV}) .{ }^{33}$ The values of the inter-band transition threshold are $571 \mathrm{~nm}(2.17$ $\mathrm{eV}), 623 \mathrm{~nm}(1.99 \mathrm{eV})$ and $620 \mathrm{~nm}(2.00 \mathrm{eV})$, for the 1500, 3000, and 5000 cycles samples, respectively, in relatively good agreement with the value of $590 \mathrm{~nm}(2.1 \mathrm{eV})$ reported for bulk $\mathrm{Cu}$. 
$\mathbf{a}$

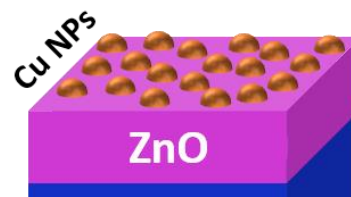

Si substrate
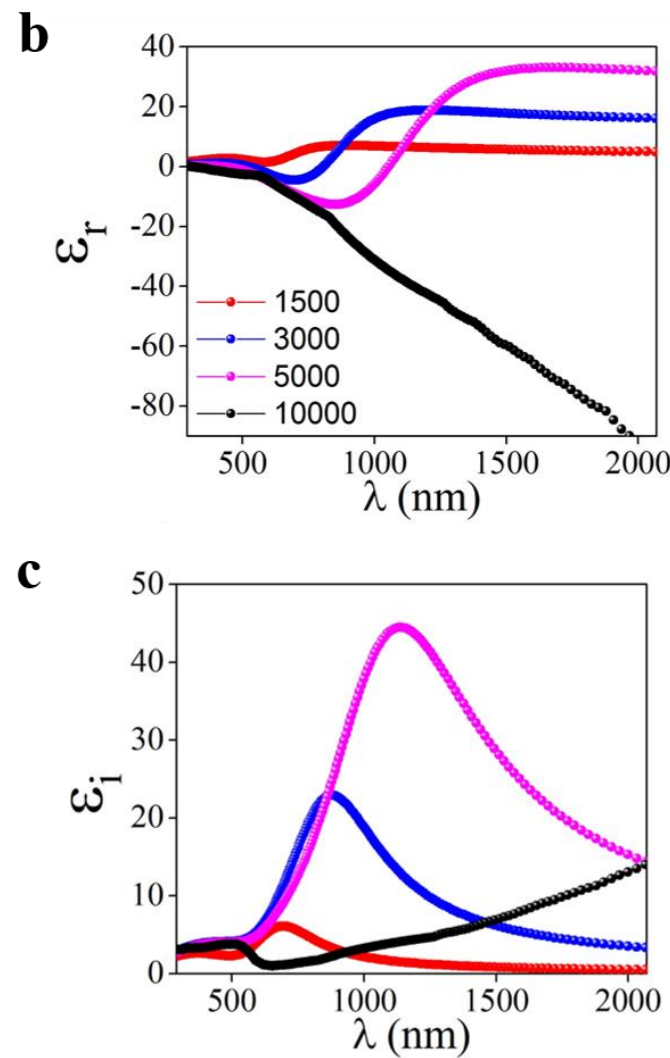

Figure 3. Schematic of the physical model used for fitting the ellipsometry data (a). Real (b) and imaginary (c) parts of the dielectric function of the $\mathrm{Cu}$ NP (color lines) and the $\mathrm{Cu}$ film (black line).

\section{Photo-response of Cu NP under visible light}

In order to verify the photo-response capability of the plasmonic $\mathrm{Cu} \mathrm{NP/ZnO}$ device, conductive atomic force microscopy (C-AFM) measurements were performed in dark and under illumination with a white light LED (5700 K, spectra from $400 \mathrm{~nm}$ to $800 \mathrm{~nm})$. A schematic of the configuration employed for the C-AFM measurements is presented in Figure 
4a. The AFM tip was in contact with the $\mathrm{Cu}$ NP and a gold back contact was sputtered on the $\mathrm{ZnO}$ film. Only the sample with $\mathrm{Cu}$ NP deposited at 1500 ALD cycles was tested since it has a LSPR band centered at $697 \mathrm{~nm}$. For the other samples, with LSPR bands in the IR region of the electromagnetic spectrum, no excitation should be expected with the used LED.

Dark and under LED illumination current density-voltage $(\mathrm{J}-\mathrm{V})$ characteristics of the sample are shown in Figure 4b. Knowing the AFM tip radius of $100 \mathrm{~nm}$, and considering it was in contact with more than one particle, a lower approximation of the current density was calculated approximating the contact area by $4315 \mathrm{~nm}^{2}$ (see Supporting Information, Figure S8). Both Ohmic contact or a Schottky junction have been reported between $\mathrm{ZnO}$ and metallic $\mathrm{Cu} .{ }^{34,35,36}$ This is due to the similar work function values between $\mathrm{Cu}(4.59-4.98)^{37}$ and $\mathrm{ZnO}\left(4.3^{38}-4.71^{39}\right)$ and to the fact that they can vary largely depending on surface preparation, structure, morphology and point defect densities. ${ }^{40}$ In our case, the formation of a Schottky junction between $\mathrm{Cu}$ and $\mathrm{ZnO}$ was previously verified by macro-electrical measurements for the compact $\mathrm{Cu}$ film/ $\mathrm{ZnO}$ (see Figure S9, Supporting Information). In the case of the $\mathrm{Cu} \mathrm{NP/ZnO}$ structure an almost symmetric J-V curve was obtained by C-AFM. This result is due to the formation of two Schottky junctions at the $\mathrm{Cu} N P / \mathrm{ZnO}$ and $\mathrm{ZnO} / \mathrm{Au}$ (back contact) interfaces, since symmetrical J-V characteristics are typical of back-to-back Schottky devices. ${ }^{41,42,43}$ The formation of the back contact between $\mathrm{ZnO}$ and $\mathrm{Au}$ is expected since the work function of $\mathrm{Au}(5.31-5.47 \mathrm{eV}){ }^{37,44}$ is much higher than that of $\mathrm{ZnO} .{ }^{45}$

The J-V curve under illumination with the white LED (red line) shows a significant increase in the current density, which confirms the photosensitivity of the device. Moreover, the current density under illumination gradually increases (almost linearly) with the increase of the reverse bias voltage from 0 to $-6 \mathrm{~V}$. The dark current observed for reverse bias voltages arises from thermionic emission. ${ }^{45}$

The responsivity $(\mathrm{R})$ of the device was calculated by the formula, ${ }^{46}$ 


$$
R=\frac{J_{p h}}{P_{\text {opt }}}
$$

Where, $P_{o p t}$ is the incident power density on the device and $J_{p h}$ is the photocurrent calculated by subtracting the dark current $\left(J_{D}\right)$ from the current under illumination $\left(J_{L}\right)$. The sample responsivity is plotted in Figure $4 \mathrm{c}$ as a function of the reverse bias voltage. The highest responsivity was of $\sim 0.10 \mathrm{~A} / \mathrm{W}$, obtained at a bias voltage of $-6 \mathrm{~V}(\lambda=400-$ $800 \mathrm{~nm}, P_{\text {opt }}=7 \mathrm{~W} / \mathrm{cm}^{2}$ ) in the same order to values reported for other $\mathrm{Cu}-\mathrm{ZnO}$-based visible photodetector at $10 \mathrm{~V} .{ }^{47}$

Figure $4 \mathrm{c}$ shows the evolution of the current as a function of the applied bias voltage during dark/light cycles of $20 \mathrm{~s}$ (during these measurements the AFM tip was stationary on the NP). A photocurrent is detected whenever light is on, confirming that the device can be on/off switched keeping a good stability. In order to describe the response speed of the photodetector, the rise and recovery times were calculated from the current vs. time curves at different applied voltages under dark/light cycles of 20 s (see Figure S10 of Supporting Information). The rise time, defined as the time difference between the 10 and $90 \%$ points of the maximum amplitude of the current pulse, is between 0.50 and $0.75 \mathrm{~s}$ for measurements under different bias voltages. The recovery time, defined as the time difference between the 90 and $10 \%$ points of the maximum amplitude of the current pulse during the trailing edge of the pulse, is between 0.54 and $0.67 \mathrm{~s}$. These response times are promising considering the values that have been reported for some $\mathrm{Cu}-\mathrm{ZnO}$-based visible photodetectors of $8 \mathrm{~s}$ and 1723 s. $^{47,48}$ 
a

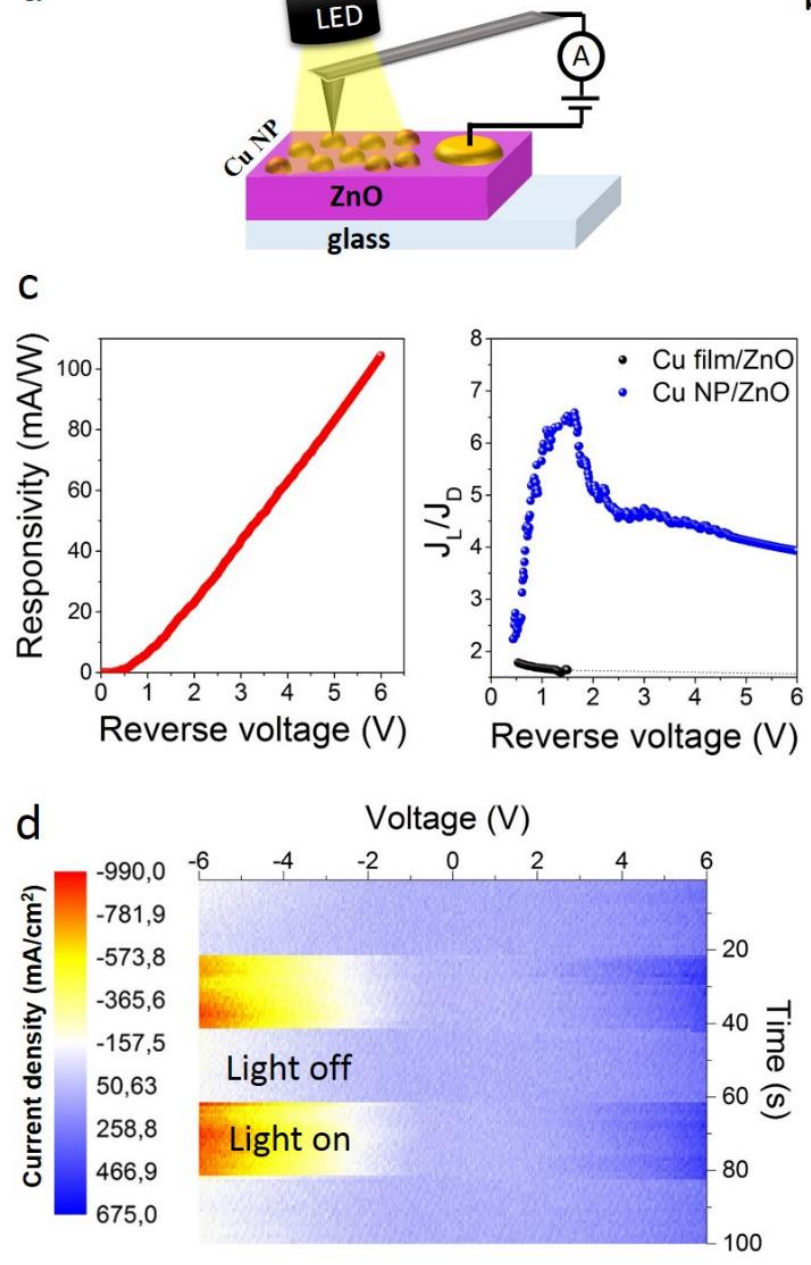

b

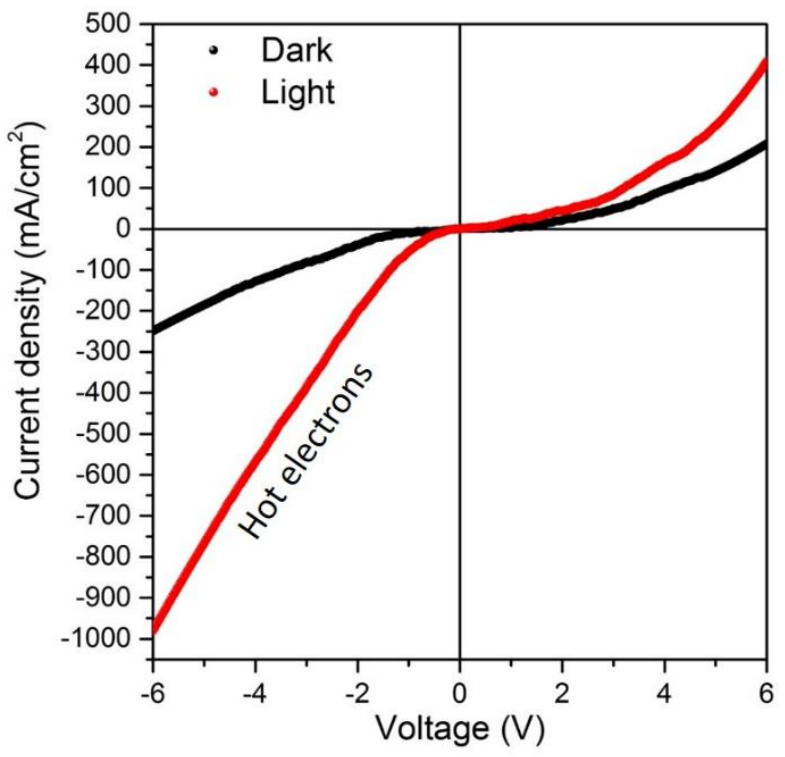

e

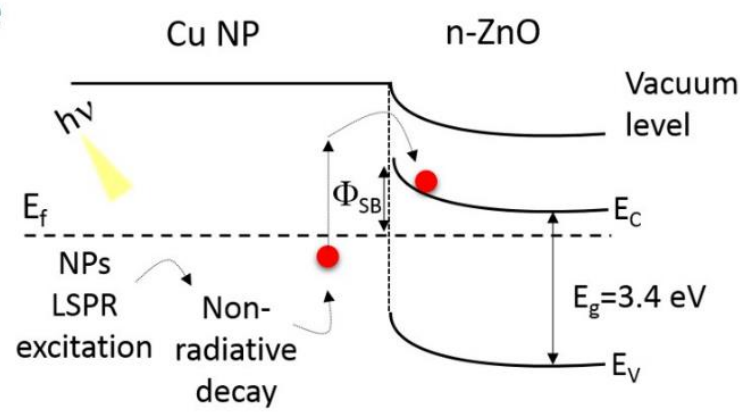

Figure 4. Photo-response of $\mathrm{Cu} \mathrm{NP}$ under visible light. Schematic of the C-AFM measurements (a). Current density-voltage characteristics of the $\mathrm{Cu} \mathrm{NP} / \mathrm{ZnO}$ device on dark and under visible light illumination, estimated contact area of $4315 \mathrm{~nm}^{2}$ (b). Responsivity and $J_{L} / J_{D}$ ratio as a function of the reverse voltage (c). Current density evolution as a function of the applied bias voltage during dark/light cycles of $20 \mathrm{~s}(\mathrm{~d})$. Schematic illustration of the energy band alignment at the $\mathrm{Cu} \mathrm{NP} / \mathrm{ZnO}$ interface together with the representation of hot electron generation at the $\mathrm{Cu} \mathrm{NP}$ and the transfer to the $\mathrm{ZnO}$ through the Schottky barrier (e).

Since $\mathrm{ZnO}$ exhibits a wide band gap of $3.3 \mathrm{eV}$, there is no significant absorption (unless a weak one related with some defect levels within the band gap) when illuminated with white light. Furthermore, for the traditional Schottky junction formed between $\mathrm{Cu}$ and $\mathrm{ZnO}$ thin films (sample deposited at 10000 ALD cycles, see Supporting Information Figure S9) the 
ratio $J_{L} / J_{D}$ was of 1.65 at $-1 \mathrm{~V}$ which represent less than $30 \%$ of the ratio of 5.86 obtained for the $\mathrm{Cu} \mathrm{NP} / \mathrm{ZnO}$ at the same bias voltage (see Figure 4c). Therefore, the significant increase in the photocurrent observed here can be univocally attributed to the effect of the $\mathrm{Cu}$ NP. We propose that it is the result of hot-electron generation from $\mathrm{Cu}$ NP upon LSPR decay, and injection into the $\mathrm{ZnO}$ film. When white light illuminates the sample, LSPR excitation occurs in the $\mathrm{Cu}$ NP. In the case of non-radiative decay, energy is transferred to hot electrons that become excited above the fermi level (see Figure 4e). Electrons in the $\mathrm{Cu}$ NP having sufficient energy to overcome the Schottky barrier are injected into the $\mathrm{ZnO}$ semiconductor. A rough estimation of the Schottky barrier for the $\mathrm{Cu} / \mathrm{ZnO}$ structure of $0.7 \mathrm{eV}$ was calculated using the thermionic emission-theory ${ }^{49}$ (see Figure S9, Supporting Information). For noble metal NP, the hot-electron energies are usually in the range of 1 to $4 \mathrm{eV}$ above the Fermi level. ${ }^{50,13}$ Hence, they can easily overcome the Schottky barrier and be injected into the $\mathrm{ZnO}$ film, resulting in photocurrent generation. Since the electrons are injected into the semiconductor, the plasmonic NP are left positively charged, however the charge is balanced as the device is connected to an external circuit. A reverse bias provides the necessary electrons to keep the charge balanced and the current flowing in the device. Moreover, increasing the negative bias favors electron injection form $\mathrm{Cu}$ NP to the conduction band of $\mathrm{ZnO}$, increasing the photocurrent.

\section{Conclusion}

We have shown that $\mathrm{Cu}$ NP deposited by ALD on ZnO films hold LSPR with plasmon wavelength tunable continuously between the visible near-infrared by changing the NP size and separation, parameters that are controlled by the number of ALD cycles. $\mathrm{Cu}$ films could also be produced at large number of ALD cycles. A highly-responsive visible light photodetector was fabricated based on hot electron injection from $\mathrm{Cu}$ NP exhibiting LSPR to 
$\mathrm{ZnO}$ thin films as demonstrated by C-AFM measurements. The significant photoresponse and fast response times of $\mathrm{Cu} \mathrm{NP/ZnO}$ device together with the possibility of tuning the LSPR band between the visible and near-infrared region of the electromagnetic spectrum open an avenue towards the development of new systems for plasmon-enhanced light-emitting and photovoltaic devices. The deposition of $\mathrm{Cu}$ NP by ALD offers the possibility to cover high aspect ratio structures and complex 3D surfaces, which is highly demanded for applications related with gas sensing, plasmon catalysis and plasmonic energy conversion.

\section{Experimental Section}

$\mathrm{ZnO}$ films were grown by reactive magnetron sputtering on Si (100) and glass substrates using a $\mathrm{Zn}$ metallic target (99.99\%). For the deposition $\mathrm{Ar}$ and $\mathrm{O}_{2}$ flow rates of 50 and 6 sccm were used, respectively. The base pressure in the chamber was around $10^{-3} \mathrm{~Pa}$ and the total pressure during deposition was kept at $0.5 \mathrm{~Pa}$. A current of $0.07 \mathrm{~A}$ was applied to the $\mathrm{Zn}$ target. $\mathrm{Cu} \mathrm{NP}$ and $\mathrm{Cu}$ thin films were grown on $\mathrm{ZnO}$ by atomic layer deposition in a ALD PICOSUN ${ }^{\text {TM }}$ R-200 Advanced Reactor. Cu(hfac) $)_{2}(99.99+\%-C u$ purity) was used as copper precursor and deionized water was employed as reactant. The substrate temperature was of $280^{\circ} \mathrm{C}$ and the pressure in the ALD chamber was of $8 \mathrm{hPa}$. A four-step ALD deposition process consisting on $1 \mathrm{~s}$ of $\mathrm{Cu}(\mathrm{hfac})_{2}$ pulse and $3 \mathrm{~s}$ of water pulse separated by $6 \mathrm{~s}$ of $\mathrm{N}_{2}$ purge was employed. Different number of ALD cycles were used ranging from 20 to 10000. More details on both the sputtering and ALD processes can be found in de Melo et. al. ${ }^{19}$

Ellipsometric measurements were performed with a phase modulation ellipsometer (UVISEL, Horiba). Scanning electron micrographs of the $\mathrm{Cu}$ NP were performed at $5 \mathrm{kV}$ in a Philips XL-30 S-FEG SEM. The average NP $\mathrm{LS}_{\text {S }}$ distribution was determined with the Image $\mathrm{J}$ (1.51n) software by measuring the diameter of individual NP. X-ray diffractograms of the samples were obtained in a diffractometer (Bruker D8 Advanced) using $\mathrm{K}_{\alpha 1}$ radiation of $\mathrm{Cu}$ 
(wavelength $\lambda=0.15406 \mathrm{~nm}$ ) in the $\theta-2 \theta$ configuration. X-ray photoelectron spectroscopy was performed to the $\mathrm{Cu} \mathrm{NP}$ under Mg Ka X-rays (1253.6 eV). Transmission electron microscopy analysis of the $\mathrm{Cu} \mathrm{NP}$ and the $\mathrm{Cu}$ film were carried out in a JEOL ARM 200F Cold FEG TEM/STEM operating at $200 \mathrm{kV}$. The TEM lamella was prepared by focused ion beam (Helios 600i-FEI). The resistivity of the $\mathrm{Cu}$ film was measure by the four-point probe method in a linear configuration. The electrical measurements for the $\mathrm{Cu} / \mathrm{ZnO}$ Schottky junction were performed by a source picometer (Keithley 2401) using two metallic needles as contact. For the electrical characterization of the $\mathrm{CuNP} / \mathrm{ZnO}$ device conductive atomic force microscopy measurements were performed in contact mode using a NTEGRA AFM (NT-MDT) system. For these measurements a N-doped diamond coated probe (DCP20) was used (height $=10$ $\mu \mathrm{m}$, radius $=100 \mathrm{~nm})$. For the measurements under illumination a Thorlabs white LED was used with $5700 \mathrm{~K}$ color temperature, emission spectra from $400 \mathrm{~nm}$ to $800 \mathrm{~nm}$ and maximum output power of $4.6 \mathrm{~W}$.

\section{ASSOCIATED CONTENT}

Supporting Information. Additional figures and data (NP height, coherence length and average lateral NP size for the $\mathrm{Cu} \mathrm{NP}$, top-view SEM micrograph of the $\mathrm{Cu}$ film, XPS measurements, ellipsometric models and fitting for all the samples studied, estimation of the AFM tip contact area and current density-voltage characteristics of the $\mathrm{Cu}$ film/ZnO Schottky junction) (PDF).

\section{AUTHOR INFORMATION}

\section{Corresponding Author}

*E-mail: david.horwat@univ-lorraine.fr

\section{ORCID}


David Horwat: 0000-0001-7938-7647

\section{Author Contributions}

D. H., M. J., J. F. P., F. M and F. M. conceived the experiment and supervise the work. C. de M. performed the experiments and wrote the manuscript. Y. B. and A. E. performed the ellipsometry measurement and modeling. F. R., A. V. and N. A. conducted the C-AFM measurements. J. G. performed the TEM analysis and S. M. prepared the TEM lamella. The results were discussed by all the authors.

\section{Funding Sources}

Erasmus Mundus Ph.D. fellowship doctoral program DocMASE (Project 2015-03)

Université franco-allemande (UFA) $\mathrm{PhD}$ track "German/French Graduate School in Materials Science and Engineering" (PhD02-14)

Carl Tryggers Foundation (CTS16:13, CTS17:24)

Kempe Foundations (SMK-2546)

Knut and Alice Wallenberg Foundation

Notes

The authors declare no competing financial interest.

\section{ACKNOWLEDGMENT}

C. de Melo deeply acknowledges the European Commission for the Erasmus Mundus PhD fellowship under the DocMASE program (Project 2015-03) and the Université francoallemande (UFA) for the financial aids under the PhD-track in Materials Science and Engineering (\#PhD02-14). The authors acknowledge the Davm center at Institut Jean Lamour for the access to the ALD and XPS facilities. The authors thank Alexandre Boucher for the assistance during the XPS measurements. F. Rigoni acknowledges the Carl Tryggers Foundation (CTS16:13, CTS17:24) for the postdoctoral fellowship. N. Almqvist and A. 
Vomiero acknowledge the Kempe Foundations (SMK-2546) and the Knut and Alice Wallenberg Foundation for funding of the AFM equipment and for partial funding, respectively.

\section{ABBREVIATIONS}

ALD, atomic layer deposition; NP, nanoparticles; LSPR, localized surface plasmon resonance; SEM, scanning electron microscopy; $\mathrm{NP}_{\mathrm{LS}}$, the lateral $\mathrm{NP}$ size; $\mathrm{RF}$, relative frequency; TEM, transmission electron microscopy; HR-TEM, high resolution transmission electron microscopy; FFT, fast Fourier transform pattern; J-V, current density - voltage; CAFM, conductive atomic force microscopy; FIB, focused ion beam; NIR, near infrared.

\section{REFERENCES}

(1) Stanley, R. Plasmonics in the Mid-Infrared. Nat. Photonics 2012, 6, 409-411.

(2) Jiang, T.; Jia, C.; Zhang, L.; He, S.; Sang, Y.; Li, H.; Li, Y.; Xu, X.; Liu, H. Gold and Gold-palladium Alloy Nanoparticles on Heterostructured $\mathrm{TiO}_{2}$ Nanobelts as Plasmonic Photocatalysts for Benzyl Alcohol Oxidation. Nanoscale 2015, 7 (1), 209-217.

(3) Hutter, E.; Fendler, J. H. Exploitation of Localized Surface Plasmon Resonance. Adv. Mater. 2004, 16 (19), 1685-1706.

(4) Chou, C.-H.; Chen, F.-C. Plasmonic Nanostructures for Light Trapping in Organic Photovoltaic Devices. Nanoscale 2014, 6 (15), 8444-8458.

(5) Souza, M. L. de; Corio, P.; Brolo, A. G. Cu Nanoparticles Enable PlasmonicImproved Silicon Photovoltaic Devices. Phys. Chem. Chem. Phys. 2012, 14 (45), 1572215728. 
(6) Yibi, Y.; Chen, J.; Xue, J.; Song, J.; Zeng, H. Enhancement of Adjustable Localized Surface Plasmon Resonance in ZnO Nanocrystals via a Dual Doping Approach. Sci. Bull. 2017, $62(10), 693-699$.

(7) Liu, P.; Wang, H.; Li, X.; Rui, M.; Zeng, H. Localized Surface Plasmon Resonance of Cu Nanoparticles by Laser Ablation in Liquid Media. RSC Adv. 2015, 5 (97), 79738-79745.

(8) Song, J.; Li, J.; Xu, J.; Zeng, H. Superstable Transparent Conductive $\mathrm{Cu@Cu} 4 \mathrm{Ni}$ Nanowire Elastomer Composites against Oxidation, Bending, Stretching, and Twisting for Flexible and Stretchable Optoelectronics. Nano Lett. 2014, 14 (11), 6298-6305.

(9) Song, J.; Kulinich, S. A.; Li, J.; Liu, Y.; Zeng, H. A General One-Pot Strategy for the Synthesis of High-Performance Transparent-Conducting-Oxide Nanocrystal Inks for AllSolution-Processed Devices. Angew. Chem. 2015, 127 (2), 472-476.

(10) Janotti, A.; Van de Walle, C. G. Fundamentals of Zinc Oxide as a Semiconductor. Rep. Prog. Phys. 2009, 72 (12), 126501.

(11) Behrens, M.; Studt, F.; Kasatkin, I.; Kühl, S.; Hävecker, M.; Abild-Pedersen, F.; Zander, S.; Girgsdies, F.; Kurr, P.; Kniep, B.-L.; Tovar, M.; Fischer, R. W.; Nørskov, J. K.; Schlögl, R. The Active Site of Methanol Synthesis over $\mathrm{Cu} / \mathrm{ZnO} / \mathrm{Al}_{2} \mathrm{O}_{3}$ Industrial Catalysts. Science 2012, 336 (6083), 893-897.

(12) Han, Z.; Wei, L.; Zhang, Z.; Zhang, X.; Pan, H.; Chen, J. Visible-Light Photocatalytic Application of Hierarchical $\mathrm{Au}-\mathrm{ZnO}$ Flower-Rod Heterostructures via Surface Plasmon Resonance. Plasmonics 2013, 8 (2), 1193-1202.

(13) Clavero, C. Plasmon-Induced Hot-Electron Generation at Nanoparticle/Metal-Oxide Interfaces for Photovoltaic and Photocatalytic Devices. Nat. Photonics 2014, 8, 95-103. 
(14) Gogurla, N.; Sinha, A. K.; Santra, S.; Manna, S.; Ray, S. K. Multifunctional Au-ZnO Plasmonic Nanostructures for Enhanced UV Photodetector and Room Temperature NO Sensing Devices. Sci. Rep. 2014, 4 (1), 6483-6492.

(15) Pescaglini, A.; Martín, A.; Cammi, D.; Juska, G.; Ronning, C.; Pelucchi, E.; Iacopino, D. Hot-Electron Injection in Au Nanorod-ZnO Nanowire Hybrid Device for Near-Infrared Photodetection. Nano Lett. 2014, 14 (11), 6202-6209.

(16) Chan, G. H.; Zhao, J.; Hicks, E. M.; Schatz, G. C.; Van Duyne, R. P. Plasmonic Properties of Copper Nanoparticles Fabricated by Nanosphere Lithography. Nano Lett. 2007, 7 (7), 1947-1952.

(17) Wei, C.; Liu, Q. Shape-, Size-, and Density-Tunable Synthesis and Optical Properties of Copper Nanoparticles. CrystEngComm 2017, 19 (24), 3254-3262.

(18) Khan, A.; Rashid, A.; Younas, R.; Chong, R. A Chemical Reduction Approach to the Synthesis of Copper Nanoparticles. Int. Nano Lett. 2016, 6 (1), 21-26.

(19) de Melo, C.; Jullien, M.; Ghanbaja, J.; Montaigne, F.; Pierson, J.-F.; Soldera, F.; Rigoni, F.; Almqvist, N.; Vomiero, A.; Mücklich, F.; Horwat, D. Local Structure and PointDefect-Dependent Area-Selective Atomic Layer Deposition Approach for Facile Synthesis of p- $\mathrm{Cu}_{2} \mathrm{O} / \mathrm{n}-\mathrm{ZnO}$ Segmented Nanojunctions. ACS Appl. Mater. Interfaces 2018, 10 (43), $37671-37678$.

(20) Shrestha, P.; Gu, D.; Tran, N.; Tapily, K.; Baumgart, H.; Namkoong, G. Investigation of Volmer-Weber Growth during the Nucleation Phase of ALD Platinum Thin Films and Template Based Platinum Nanotubes. ECS Trans. 2010, 33 (2), 127-134.

(21) Puurunen, R. L.; Vandervorst, W. Island Growth as a Growth Mode in Atomic Layer Deposition: A Phenomenological Model. J. Appl. Phys. 2004, 96 (12), 7686-7695. 
(22) de Vries, J. W. C.; den Broeder, F. J. A. Influence of Interface Scattering on the Resistance of Polycrystalline Au/Pd Multilayered Thin Films. J. Phys. F Met. Phys. 1988, 18 (12), 2635-2647.

(23) Gall, D. Electron Mean Free Path in Elemental Metals. J. Appl. Phys. 2016, 119 (8), 085101.

(24) Battie, Y.; En Naciri, A.; Vergnat, M. Plasmonic and Metallic Optical Properties of $\mathrm{Au} / \mathrm{SiO}_{2}$ Metal-Insulator Films. J. Appl. Phys. 2017, 122 (21), 213101.

(25) Moirangthem, R. S.; Chang, Y.-C.; Wei, P.-K. Ellipsometry Study on GoldNanoparticle-Coated Gold Thin Film for Biosensing Application. Biomed. Opt. Express 2011, 2 (9), 2569-2576.

(26) Reinhard, B. M.; Siu, M.; Agarwal, H.; Alivisatos, A. P.; Liphardt, J. Calibration of Dynamic Molecular Rulers Based on Plasmon Coupling between Gold Nanoparticles. Nano Lett. 2005, 5 (11), 2246-2252.

(27) Ghosh, S. K.; Pal, T. Interparticle Coupling Effect on the Surface Plasmon Resonance of Gold Nanoparticles: From Theory to Applications. Chem. Rev. 2007, 107 (11), 47974862.

(28) Mock, J. J.; Barbic, M.; Smith, D. R.; Schultz, D. A.; Schultz, S. Shape Effects in Plasmon Resonance of Individual Colloidal Silver Nanoparticles. J. Chem. Phys. 2002, 116 (15), 6755-6759.

(29) Kelly, K. L.; Coronado, E.; Zhao, L. L.; Schatz, G. C. The Optical Properties of Metal Nanoparticles: The Influence of Size, Shape, and Dielectric Environment. J. Phys. Chem. B 2003, 107 (3), 668-677. 
(30) Vieaud, J.; Gao, J.; Cane, J.; Stchakovsky, M.; En Naciri, A.; Ariga, K.; Oda, R.; Pouget, E.; Battie, Y. Gold Nanoparticle Chains: Synthesis, Characterization, and Modeling Using Spectroscopic Ellipsometry. J. Phys. Chem. C 2018, 122 (22), 11973-11984.

(31) Zhong, Z.; Patskovskyy, S.; Bouvrette, P.; Luong, J. H. T.; Gedanken, A. The Surface Chemistry of Au Colloids and Their Interactions with Functional Amino Acids. J. Phys. Chem. B 2004, 108 (13), 4046-4052.

(32) Lin, S.; Li, M.; Dujardin, E.; Girard, C.; Mann, S. One-Dimensional Plasmon Coupling by Facile Self-Assembly of Gold Nanoparticles into Branched Chain Networks. Adv. Mater. 2005, 17 (21), 2553-2559.

(33) Ziashahabi, A.; Ghodselahi, T.; Heidari saani, M. Localized Surface Plasmon Resonance Properties of Copper Nano-Clusters: A Theoretical Study of Size Dependence. $J$. Phys. Chem. Solids 2013, 74 (7), 929-933.

(34) Khan, A.; Hussain, M.; Abbasi, M. A.; Ibupoto, Z. H.; Nur, O.; Willander, M. Study of Transport Properties of Copper/Zinc-Oxide-Nanorods-Based Schottky Diode Fabricated on Textile Fabric. Semicond. Sci. Technol. 2013, 28 (12), 125006.

(35) Brillson, L. J.; Lu, Y. ZnO Schottky Barriers and Ohmic Contacts. J. Appl. Phys. 2011, 109 (12), 121301.

(36) Muhammed Shafi, K.; Vinodkumar, R.; Bose, R. J.; Uvais, V. N.; Mahadevan Pillai, V. P. Effect of $\mathrm{Cu}$ on the Microstructure and Electrical Properties of $\mathrm{Cu} / \mathrm{ZnO}$ Thin Films. $J$. Alloys Compd. 2013, 551, 243-248.

(37) Michaelson, H. B. The Work Function of the Elements and Its Periodicity. J. Appl. Phys. 1977, 48 (11), 4729-4733. 
(38) Lange, I.; Reiter, S.; Pätzel, M.; Zykov, A.; Nefedov, A.; Hildebrandt, J.; Hecht, S.; Kowarik, S.; Wöll, C.; Heimel, G.; Neher, D. Tuning the Work Function of Polar Zinc Oxide Surfaces Using Modified Phosphonic Acid Self-Assembled Monolayers. Adv. Funct. Mater. 2014, 24 (44), 7014-7024.

(39) Wei, M.; Li, C.-F.; Deng, X.-R.; Deng, H. Surface Work Function of Transparent Conductive ZnO Films. Energy Procedia 2012, 16, 76-80.

(40) Kahn, A. Fermi Level, Work Function and Vacuum Level. Mater. Horiz. 2016, 3 (1), 7-10.

(41) Kus,demir, E.; Özkendir, D.; Fırat, V.; Çelebi, C. Epitaxial Graphene Contact Electrode for Silicon Carbide Based Ultraviolet Photodetector. J. Phys. Appl. Phys. 2015, 48 (9), 095104.

(42) Samanta, S.; Das, K.; Raychaudhuri, A. K. Junction Effect on Transport Properties of a Single Si Nanowire Metal-Semiconductor-Metal Device. IEEE Trans. Nanotechnol. 2013, $12(6), 1089-1093$.

(43) Osvald, J. Back-to-Back Connected Asymmetric Schottky Diodes with Series Resistance as a Single Diode. Phys. Status Solidi A 2015, 212 (12), 2754-2758.

(44) Sachtler, W. M. H.; Dorgelo, G. J. H.; Holscher, A. A. The Work Function of Gold. Surf. Sci. 1966, 5 (2), 221-229.

(45) Rhoderick, E. H. Metal-Semiconductor Contacts. IEE Proc. - Solid-State Electron Devices 1982, $129(1), 1-14$.

(46) Goykhman, I.; Sassi, U.; Desiatov, B.; Mazurski, N.; Milana, S.; de Fazio, D.; Eiden, A.; Khurgin, J.; Shappir, J.; Levy, U.; et al. On-Chip Integrated, Silicon-Graphene Plasmonic 
Schottky Photodetector with High Responsivity and Avalanche Photogain. Nano Lett. 2016, $16(5), 3005-3013$.

(47) Hu, L.; Zhu, L.; He, H.; Guo, Y.; Pan, G.; Jiang, J.; Jin, Y.; Sun, L.; Ye, Z. Colloidal Chemically Fabricated $\mathrm{ZnO}$ : $\mathrm{Cu}$-Based Photodetector with Extended UV-Visible Detection Waveband. Nanoscale 2013, 5 (20), 9577-9581.

(48) Kouklin, N. Cu-Doped ZnO Nanowires for Efficient and Multispectral Photodetection Applications. Adv. Mater. 2008, 20 (11), 2190-2194.

(49) Zhang, T.-F.; Wu, G.-A.; Wang, J.-Z.; Yu, Y.-Q.; Zhang, D.-Y.; Wang, D.-D.; Jiang, J.-B.; Wang, J.-M.; Luo, L.-B. A Sensitive Ultraviolet Light Photodiode Based on Grapheneon-Zinc Oxide Schottky Junction. Nanophotonics 2017, 6 (5), 1073-1081.

(50) Linic, S.; Christopher, P.; Ingram, D. B. Plasmonic-Metal Nanostructures for Efficient Conversion of Solar to Chemical Energy. Nat. Mater. 2011, 10 (12), 911-921. 